\title{
MeteoGIS: GIS-based system for monitoring of severe meteorological phenomena
}

\author{
Anna Jurczyk, Katarzyna Ośródka, Jan Szturc, Mateusz Giszterowicz, Paweł Przeniczny \\ Institute of Meteorology and Water Management - National Research Institute, Podleśna Street 61, 01-673 Warszawa, \\ Poland, e-mail: anna.jurczyk@imgw.pl
}

\section{Grzegorz Tkocz}

Noma2 Sp. z o.o., Prebiscytowa Street 36, 40-041 Katowice, Poland

\begin{abstract}
The MeteoGIS system developed at the Institute of Meteorology and Water Management - National Research Institute in Poland is a GIS-based system for real-time monitoring of weather and the generation of meteorological warnings. Apart from its monitoring features, it can also provide more advanced analysis, including SQL (Structured Query Language) queries and statistical analyses. Input data are provided mainly by the INCA-PL 2 nowcasting model which employs forecasts from the high-resolution AROME numerical weather prediction model and measurement data from the Polish weather radar network POLRAD and surface meteorological stations. As well as this, data from the PERUN lighting detection system are used. Ingestion of such data allows for the mitigation of risk from potentially hazardous weather phenomena such as extreme temperatures, strong wind, thunderstorms, heavy rain and subsequent impending floods. The following meteorological parameters at ground level are visualised in the MeteoGIS: (i) precipitation (accumulation and type), (ii) temperature, (iii) wind (speed and direction), (iv) lightning (locations and type). End users of the system are workers from civil protection services who are interested in shortterm warnings against severe weather events, especially area-oriented ones (related to districts, catchments, etc.). The reliability of visualised data is a very important issue, and from the MeteoGIS user's point of view the improvement in data quality is a continuous process.
\end{abstract}

Keywords: meteorological data; weather radar; GIS; monitoring, nowcasting

Submitted 3 July 2015, revised 15 October 2015, accepted 25 November 2015

\section{Introduction}

Real-time remote-sensing data and high-resolution nowcasts constitute the most important source of information in the prevention of the effects of natural hazards. Applying high-resolution meteorological data in connection with powerful tools, such as GIS (Geographic Information System) techniques, appears an effective solution for analysing, displaying and modelling different spatiotemporal environmental processes.

One example is a system from the CEDIM (Center for Disaster Management and Risk Reduction Technology) that uses web and GIS technologies (Köhler et al. 2006) to visualise various natural risks in Germany. The Weather Radar Viewer application of NOAA's (National Oceanic and Atmospheric Administration) NCDC (National Climatic Data Center) was developed (Del Greco, Ansari 2006) as a GISbased visual browser for radar data. Another example is the HDSS (Hydromet Decision Support System) system (Conway, Eilts 2004; Conway et al. 2006), which is designed for flash flood prediction based on precipitation estimates and nowcasts for the Veneto region of Italy.
The aim of the paper is to present the MeteoGIS system which enables the monitoring of weather phenomena in real time and for a few hours ahead. The system allows for the downloading of data, archiving, visualisation and the issuing of meteorological warnings in a fully automatic mode. Management of the warnings is flexible and user-friendly; the user can configure them not only in terms of thresholds but also according to specified area (catchments, districts, etc.). The system comprises many tools based on GIS techniques and SQL (Structured Query Language) queries, by means of which the user is able to analyse data in a comprehensive and precise way.

The paper is organised as follows: a general idea of the MeteoGIS system is introduced in Section 2. All meteorological input data, including algorithms of the data processing and visualisation, are described in Sections 3 and 4. The main tasks of the system - monitoring of the current weather state, the issuing of meteorological warnings, weather analyses and system management - are presented in Sections 5 and 6. An example of the system capabilities is given in Section 7. Finally, a short summary is provided in Section 8. 


\section{General description}

\subsection{The MeteoGIS approach}

The MeteoGIS is a GIS-based system for monitoring current weather conditions and issuing user-specific warnings; it also has application for the analysis of past events (Ośródka et al. 2008). Its capability to take full advantage of real-time data (from weather radar networks, meteorological stations, NWP (numerical weather prediction) models, and lightning detection systems) allows the mitigation of risk from potentially hazardous weather phenomena such as strong wind, thunderstorms, heavy rain, and floods that are consequently triggered. End users of the system are neither meteorologists nor hydrologists, but government or local authority services who are interested in short-term warnings against severe weather events, especially area oriented ones (e.g. for a selected district, catchment).

The MeteoGIS system consists of several cooperating modules (fig. 1). It is a user-friendly graphical user interface (GUI) application for the visualisation of provided meteorological data (fig. 2) which works in client-server architecture. MeteoGIS input software processes the input data, which are received via FTP protocol and stored in the dedicated database by the MeteoGIS_server service.

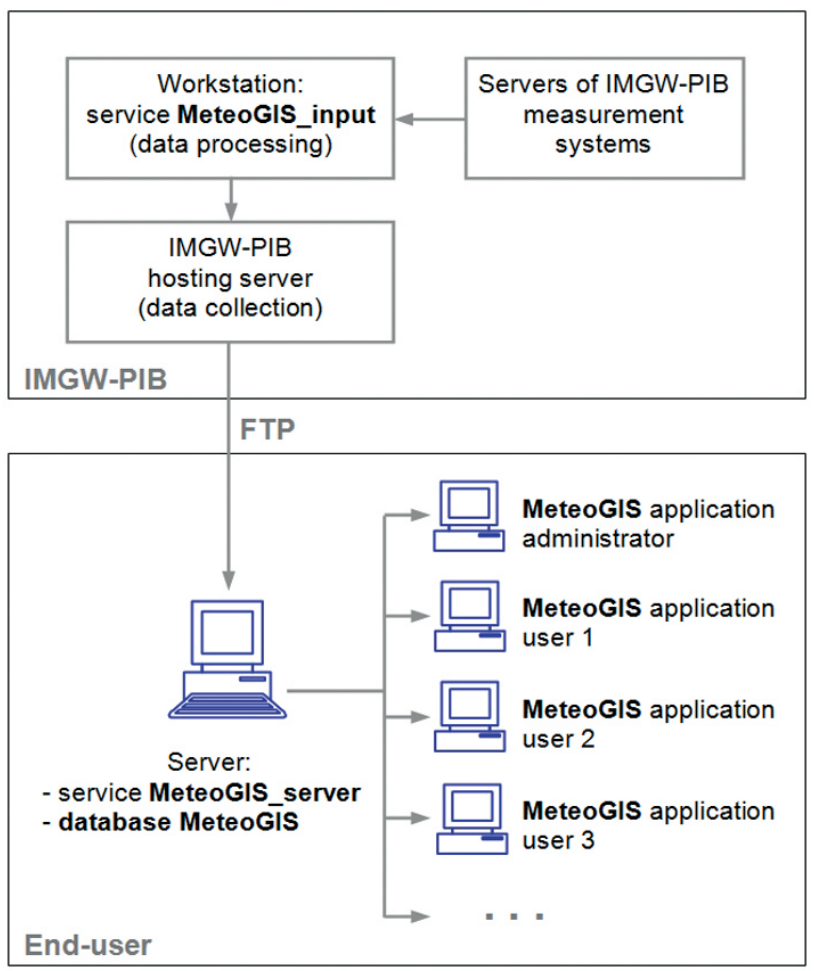

Fig. 1. General scheme of the MeteoGIS system

The system was developed at the Institute of Meteorology and Water Management - National Research Institute (IMGW-PIB) and implemented for real-time work in 2007 within the Silesian and Opole Voivodeships (provinces) authorities (Departments of Risk Management) in Poland (Jurczyk et al. 2009). In 2014, significant modernisation was carried out in terms of data sources; first of all data from the INCA-PL 2 (Integrated Nowcasting through Comprehensive Analysis) nowcasting model was incorporated into the system, and some functionalities were also modified.

Software tools employed to develop the MeteoGIS system include Delphi 2009 and TatukGIS (a commercial toolkit for GIS software development). Data is stored in an MS SQL Server relational database. An MS Windows system is required to install the MeteoGIS system.

\subsection{The MeteoGIS domain}

The MeteoGIS system can be adapted to any area; however, the improved version has been developed specifically for Upper Silesia in the south of Poland (fig. 3). The region is characterised by the highest population density in Poland and intensive industrial development. Moreover, it is one of the most important regions for flood protection as three of the largest Polish rivers have their sources or upper parts here - namely the Wisła, Odra, and Warta Rivers. Heavy precipitation events can easily form flash floods, especially due to the complex terrain topography (the Beskidy Mountains). One of the most catastrophic floods in the south of Poland was observed in July 1997 - it caused 54 fatalities and material losses of the order of several billion USD (Kundzewicz et al. 1999). The flood inundated a large part of the country (665 000 ha of land) and the number of evacuees reached 162 thousand. The historic maxima of flow rate were highly exceeded, with a return period of the order of a thousand years or more in some river cross-sections (Kundzewicz et al. 1999).

\section{Meteorological data sources}

The MeteoGIS_input software installed at IMGW-PIB is intended to generate products for the MeteoGIS application. The data sources comprise the following measurement and processing systems operated by IMGW-PIB:

- precipitation analyses generated by the RainGRS system (see Sect. 3.1), which merges precipitation data from the rain gauge network, the Polish POLRAD weather radar network, and Meteosat meteorological satellites;

- the INCA-PL 2 meteorological nowcasting system (see Sect. 3.2), which combines data from the NWP model with telemetric and remote-sensing observations. The INCA-PL 2 is based on the following inputs:

- NWP analyses and forecasts delivered by the AROME model, 


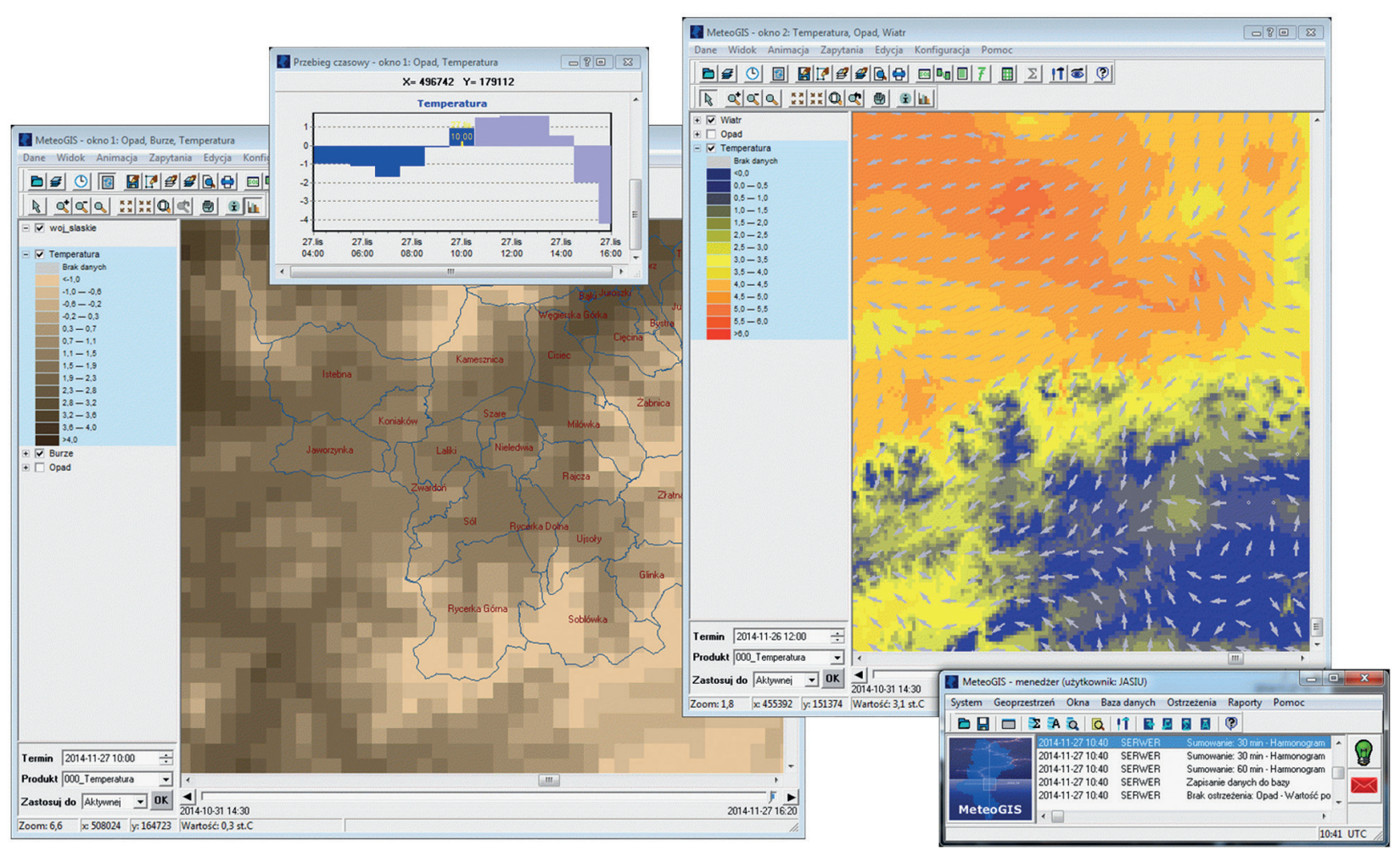

Fig. 2. Overall view of the MeteoGIS application: manager window (bottom-right), two visualisation windows and time series diagram

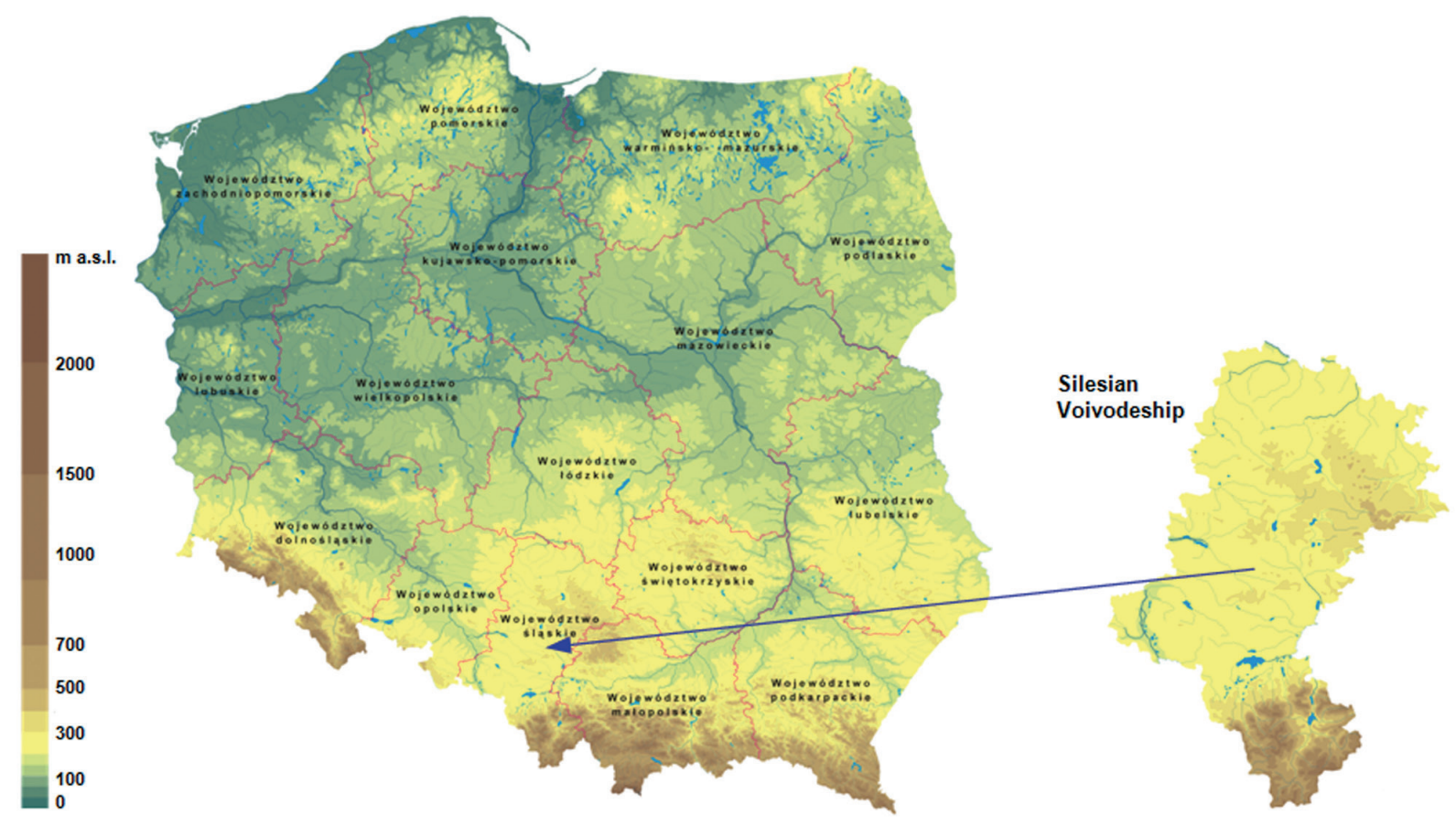

Fig. 3. Silesian Voivodeship on a map of Poland

- RainGRS precipitation analyses,

- data from the IMGW-PIB telemetric meteorological station network,

- the PERUN lightning detection system based on SAFIR 3000 type detectors (see Sect. 3.3).

Other meteorological data can also be included in the system.

All the data are converted into native MeteoGIS format, which is based on XML format with incorporated binary large objects (BLOBs). The geographical projection employed is the Polish national coordinate system 92 (PUWG 92) based on the Gauss-Krüger projection and the GRS 80 ellipsoid.

The system allows meteorological information to be accessed, displayed in the form of maps, and manipulated in a GIS environment with a versatile, user-friendly interface. It integrates diverse available weather data (both analyses and nowcasts). 


\subsection{The RainGRS: multi-source recipitation}

The surface rain is estimated in real-time by the RainGRS system of IMGW-PIB (Szturc et al., 2014) as a combination of data provided by: (i) the POLRAD weather radar network comprising eight Doppler CBand radars, including two polarimetric ones (Szturc, Dziewit 2005), (ii) a telemetric rain gauge network (consisting of 486 gauges), and (iii) visible and infrared channels of the Meteosat Second Generation meteorological satellite, after processing by NWC SAF software (NWC SAF 2013).

The input data are generated with various spatial and temporal resolutions, with different error structures specific to each data source. For each data source, specific algorithms for its quality determination are designed. The data quality is characterised by a quality index $(Q I)$, which is defined as a unitless value ranging from 0 for low-quality data to 1 for excellent data (Einfalt et al. 2010). For each kind of input data, dedicated algorithms were developed based on the determination of the most significant factors which affect the data quality and empirical formulae (Ośródka et al. 2014; Szturc et al. 2014).

The combined field denoted as GRS is generated with a $1 \mathrm{~km}$ spatial resolution every 10 minutes (corresponding to radar data temporal resolution) with the use of a quality-based algorithm. The starting point for the algorithm is conditional merging based on the Sinclair and Pegram (2005) technique, modified with quality information. The radar and satellite precipitation fields are separately adjusted to rain gauge data with the technique. The resulting gauge - radar and gauge - satellite fields are combined, applying a weight factor empirically determined from a general comparison of the reliabilities of radar and satellite precipitation.

The procedure benefits from the advantages of each kind of data, i.e. the high spatial resolution of radar observation, unbiased rain gauge data from a relatively dense gauge network, and the high availability of satellite images. All the data are quality controlled in terms of both quality characterisation (by means of the abovementioned $Q I)$ and corrections.

\subsection{The INCA-PL 2 nowcasting system}

The INCA-PL 2 is a nowcasting system developed at IMGW-PIB on the basis of the INCA system (Integrated Nowcasting through Comprehensive Analysis) (Haiden et al. 2011). The INCA was originally developed at the Central Institute for Meteorology and Geodynamics (ZAMG) which serves as the Austrian national meteorological ser- vice. In the frame of the INCA-CE (the INCA for Central Europe project, which was sponsored by the European Regional Development Fund during 2010-2013; Kann et al. 2012), the system was adapted to participating countries across Central Europe. In Poland it was adapted as INCA-PL. At present, the second version of the system (INCA-PL 2) is implemented, with significant modifications in terms of updates to the higher spatial resolution of the AROME 2.5-km model, the system domain and projection, output data format - which is HDF5 (Hierarchical Data Format 5) at present, and new precipitation analysis fields (from the RainGRS system, see Sect. 3.1).

Generally, the INCA-PL 2 is a multivariable analysis and nowcasting system. It provides near-real-time analyses and forecasts of the main meteorological fields, with a high spatial resolution of $1 \mathrm{~km}$. Its objective is to improve numerical forecast products in the nowcasting (0-6 h) and very short (up to about $8 \mathrm{~h}$ ) ranges. It also improves the NWP forecasts of up to $30 \mathrm{~h}$ through downscaling and bias correction. Spatial interpolation is based on inverse distance weighting, both in physical and variable space (potential temperature, precipitation). In the case of temperature, humidity and wind, nowcasts start with a three-dimensional analysis based on a first guess obtained from the NWP output, with observation corrections superimposed. Precipitation nowcasts are produced as an extrapolation of RainGRS analysis weighted with NWP forecasts.

The AROME is an NWP model developed by the international ALADIN consortium, from a concept devised by Météo-France. It is a non-hydrostatic model of the atmosphere. The basic parameters of the Polish installation are: spatial resolution of about $2.5 \times 2.5 \mathrm{~km}$, initialisation every 12 hours, with hourly time-steps and forecasting of up to 30 hours ahead (Seity at al. 2011).

\subsection{The PERUN: lightning detection}

Lightning locations in Poland are detected by the PERUN, which is based on the Vaisala SAFIR 3000 appliance (Konarski et al. 2008). The system is composed of nine detectors that cover the whole territory of the country.

Reports from the system are generated with 1-minute frequency and include records about each detected case of lightning. Both intracloud (IC) and cloud-to-ground (CG) lightning are detected. The quality of intracloud information, however, is not satisfactory, especially outside of the central area of the network, as was found when analysing its correlation with radar reflectivity observations. The accuracy of the determination of a lightning location is about $1 \mathrm{~km}$. 


\section{Visualised meteorological fields}

The following meteorological parameters at ground level are visualised in the MeteoGIS system:

- precipitation (accumulation and type) (Sections 4.1, 4.2 and 4.3),

- air temperature (Section 4.4),

- wind speed and direction (Section 4.5),

- lightning (locations and type) (Section 4.6).

\subsection{Precipitation 10-min accumulation}

Basic precipitation data are provided as both analyses from the RainGRS system and forecasts (nowcasts) from the INCA-PL 2 system. All the fields are generated as 10-min accumulations. The maximum lead-time of the forecasts is 6 hours. The data packages are updated every 10 min with a 1-km spatial resolution.

The precipitation field is displayed in MeteoGIS as a map with a user-defined scale and palette of colours (fig. 4) and can be processed by many GIS functionalities, described in the sections below.

\subsection{Precipitation accumulation}

The precipitation fields can be accumulated from analyses, nowcasts, or a combination of both. The computations are performed by the MeteoGIS application, so any user-defined accumulation period can be applied.

It is inevitable in operational work that some data may be missing. This makes it difficult to generate accumulations, but this should not always make it impossible. In

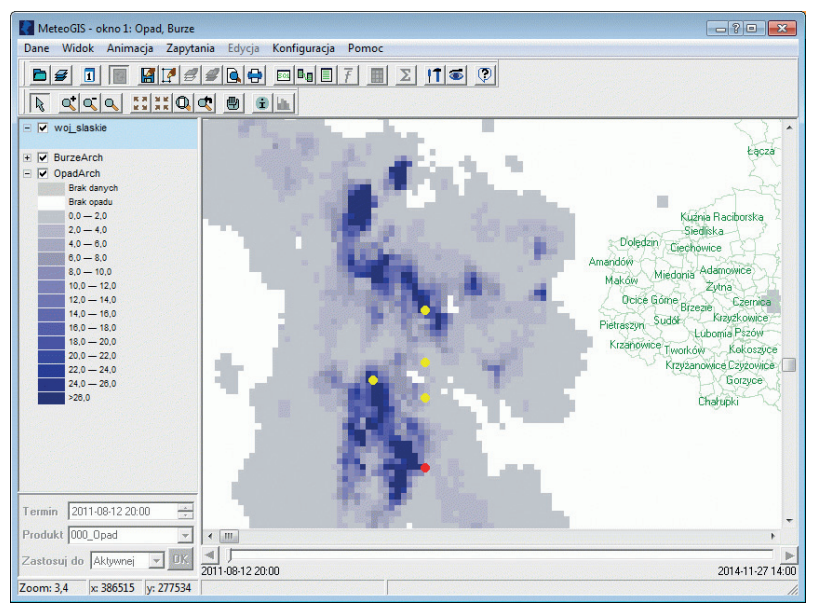

Fig. 4. Example of map of a precipitation field with lightning locations included. On the left: key of the map showing scale of precipitation (in $\mathrm{mm}$ ). Red pixels represent places where at least one instance of cloud-to-ground lightning was detected, and yellow pixels represent places where at least one instance of intracloud lightning was detected cases when gaps in an input data stream are relatively small, the accumulation should be delivered even if its reliability is decreased. The compromise between data availability and reliability should be preserved. In the developed algorithm the following parameters for accumulation retrieval are introduced:

- the maximum number of missing data (out of the total number); arbitrary number, e.g. two for an hourly accumulation,

- maximum gap between two fields, if it is longer than a 10-min time-step, e.g. $20 \mathrm{~min}$,

- how far data can be reached for beyond a given accumulation period in the case of a lack of data, counting from the start or the end of the given period.

The gaps are filled in, taking account of the spatial and temporal interpolation between two available nearby pieces of data.

\subsection{Precipitation type}

The precipitation type analyses and nowcasts are generated by the INCA-PL 2 system every hour, with a $1 \mathrm{~km}$ resolution and a lead time of up to $6 \mathrm{~h}$. The input data for the INCA-PL 2 system is delivered by the AROME NWP model. The following precipitation types are differentiated: rain, freezing rain, sleet, and snow. The precipitation type field can be displayed either by employing standard synoptic symbols or in a spatial form, just like the precipitation field.

\subsection{Air temperature}

The main source of air temperature data for the standard $2 \mathrm{~m}$ above the ground is the AROME model. The AROME forecasts are updated by the INCA-PL 2 system

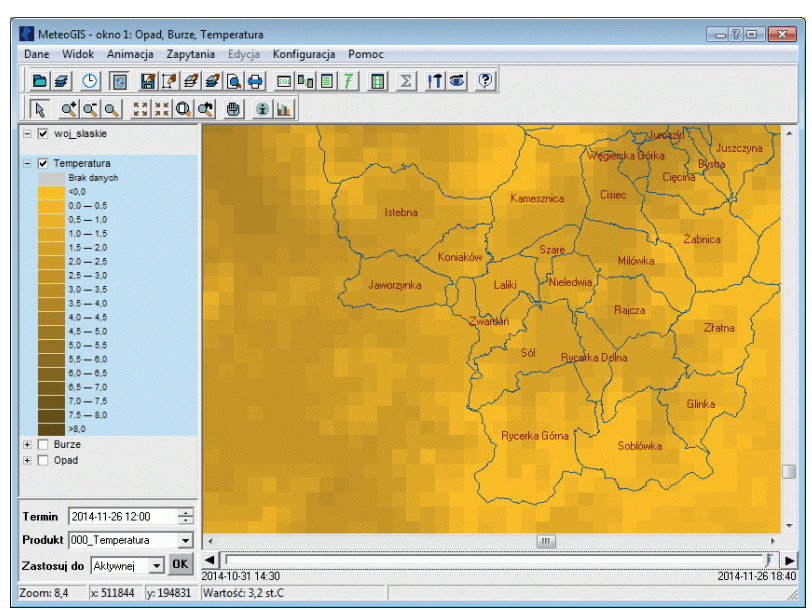

Fig. 5. Example of map of a temperature field. On the left: key showing scale in ${ }^{\circ} \mathrm{C}$. Administrative division (borders of districts) is marked in green 
with data from meteorological ground stations. The fields (analyses and forecasts) are generated every hour with $1 \mathrm{~km}$ resolution with a lead time of up to $6 \mathrm{~h}$ (fig. 5).

\subsection{Wind speed and direction}

Wind is a vectorial quantity, so two parameters should be determined for each pixel: velocity and direction. The data can be displayed in the MeteoGIS as coloured arrows, with colour representing wind velocity and the direction of the arrow showing the direction of the wind. These quantities can also be depicted as fields. Additionally, they can be overlayed over one of the other meteorological parameters using any colour palette. The wind information is provided by the AROME model for the $10 \mathrm{~m}$ level and is processed by the INCA-PL 2 system, taking into account ground measurements. The fields are generated every hour with a $1 \mathrm{~km}$ spatial resolution and a lead time of up to $6 \mathrm{~h}$ (fig. 6).

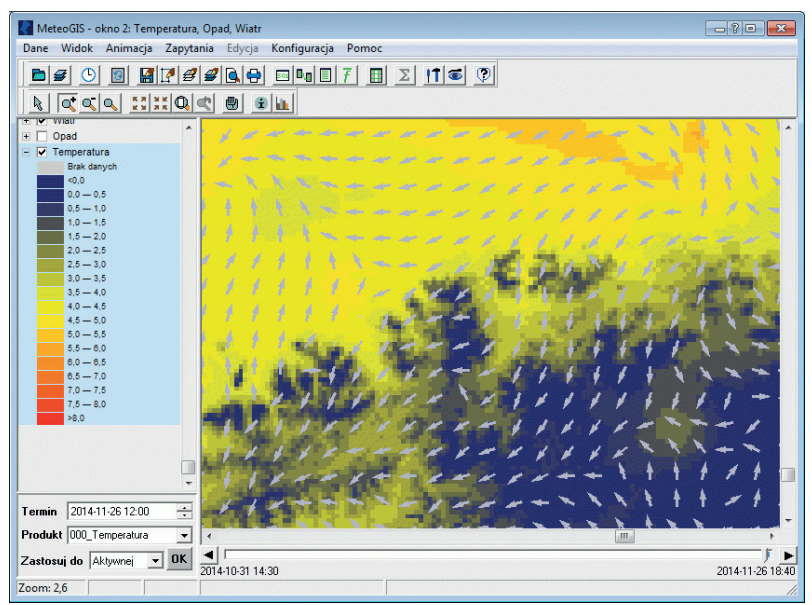

Fig. 6. Example of a wind field. The arrows indicate wind direction at given point, whereas their colours are related to wind velocity. The background can be another meteorological field here temperature is displayed

\subsection{Lightning}

Lightning locations are detected by the PERUN system. A lightning field can be displayed as two different symbols representing basic types of lightning (red for cloud-to-ground lightning and yellow for intracloud lightning) or as a spatial field, just as described above in the case of precipitation data (fig. 4). Each symbol implies at least one flash in a pixel of $1 \times 1 \mathrm{~km}$.

\section{Main tasks of the system}

The MeteoGIS system provides its users with a wide variety of information about the weather conditions in a specific region through:
- monitoring of the current weather state,

- generation of meteorological warnings,

- support for weather analyses.

\subsection{Monitoring of weather and meteorological data visualisation}

All the meteorological data fields are displayed in a visualisation window using GIS techniques. There is no limit to the number of visualisation windows with selected meteorological parameters that can be open simultaneously. Moreover, the user can overlay any geographical map in an ESRI Shapefile (SHP) format, e.g. maps of catchments, administrative borders, etc. The settings and configuration of all visualisation windows can be tailored to meet specific user needs and then saved as a workspace for future use.

The MeteoGIS application provides a high degree of flexibility - apart from all the standard GIS techniques for displaying spatial data, including configuration of a map's key, various possibilities are available to help the end user monitor the current weather. The following features implemented in the MeteoGIS will be useful for weather monitoring and visualisation:

- meteorological data downloading from a hosting server according to a preset schedule,

- automatic refresh of visualisation field after new data is available,

- animation of selected data sequences with automatic updating,

- automatic generation of precipitation accumulations for a preset time period.

\subsection{Meteorological warnings}

Meteorological warning generation is one of the most important tasks of the MeteoGIS. The warnings are to provide the civil protection services with fast and accurate information about severe weather phenomena observed or likely to occur within a few hours. The system automatically generates customisable real-time warnings if the chosen meteorological data values exceed preset critical thresholds (fig. 7).

Two kinds of warnings are introduced: one for the whole geographical domain of the system, and one for a specific area (e.g. selected objects of a GIS layer). The area-oriented warnings enable the investigation of hazardous meteorological phenomena from the perspective of a single catchment or from a selected level of local government administration. Warnings are triggered when predefined thresholds have been exceeded in incoming 


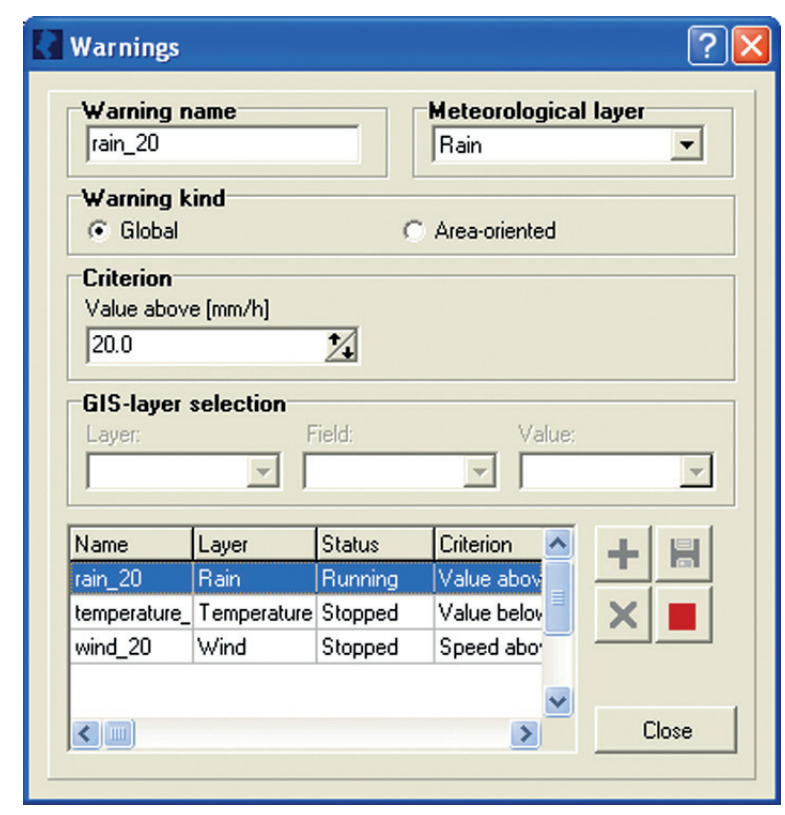

Fig. 7. Window for configuration of meteorological warnings

weather data - either analyses or forecasts. This is signalled to the user in the system manager window by displaying a message window with information, and by the meteorological warnings indicator turning red.

The MeteoGIS issues meteorological warnings in the form of plain text, which can be analysed and edited before being sent downstream as an e-mail. All the warnings are stored in a relational database and can be browsed in a dedicated report window. The warnings can be displayed for each lead time separately, as well as for the set of forecasts generated in one time-step. Examples of warning messages are presented in fig. 8 .

Examples of meteorological warnings generated on 2nd June 2015, from 1100 UTC for temperature in Zawiercie powiat (district) and from 1140 UTC for precipitation for the whole Silesian Voivodeship, are shown in fig 8 . The warning in fig. 8a notifies the user that the temperature threshold of $25.0^{\circ} \mathrm{C}$ (set by the user) will be exceeded over an area of $12 \mathrm{~km}^{2}$ in Zawiercie powiat (with a maximum of $25.2^{\circ} \mathrm{C}$ ) after 3 hours. The warning in fig. $8 \mathrm{~b}$ presents a list of districts in which 10-min precipitation accumulation exceeded or is forecast to exceed the threshold of $10 \mathrm{~mm}$ in the nearest 6 hours.

\subsection{Weather analyses}

The MeteoGIS provides a comprehensive set of tools for weather analysis and can be efficiently applied as support for decision makers. The following features are available:

- adding any geographical maps as new GIS layers; this allows a geographical location to be referred to,

- tabular presentation of meteorological data, where the end user has access to values for each pixel with its coordinates,

- generation of meteorological field statistics such as average and numbers of value classes, for the whole system domain or for selected objects of a GIS layer (e.g. for a specific catchment), which make it easier to perform quantitative analysis of meteorological parameters over the objects (see fig. 9a),

- creation of customised data layers with SQL queries: three dedicated easy-to-use editors enable users to create custom data layers using various kinds of SQL queries, such as simple or more advanced ones and employing predefined templates (e.g. identification of areas within selected Odra and Wisła catchments where precipitation accumulation exceeds a preset $20 \mathrm{~mm}$ threshold) (see fig. 9bc),

\begin{tabular}{|c|c|c|c|}
\hline \multicolumn{4}{|c|}{ E Editor of warnings } \\
\hline \multicolumn{4}{|c|}{ 国按国 } \\
\hline \multicolumn{4}{|c|}{$\begin{array}{l}\text { geteorological varning from 2015-06-02 11:34 } \\
\text { generated by HeteoGIS without meteorologist } \\
\text { Subject: 10-min precipitation accurnulation } \\
\text { data from T'2015-06-02 11:40 UTC } \\
\text { GIS-layer 'cities': all }\end{array}$} \\
\hline \multicolumn{4}{|c|}{ Values above $10.0 \mathrm{~mm} / \mathrm{h}:$} \\
\hline $\begin{array}{l}\mathrm{T}+ \\
{[\mathrm{min}]}\end{array}$ & $\begin{array}{l}\text { Maximum } \\
{[\mathrm{men} / \mathrm{h}]}\end{array}$ & $\begin{array}{l}\text { Area } \\
{\left[\mathrm{km}^{\wedge} 2\right]}\end{array}$ & Field name \\
\hline 000 & 16.8 & 52 & pow. tarnogórski \\
\hline 000 & & 66 & m. Dabrova Górnicza \\
\hline 000 & 13.5 & 47 & m. Zabrze \\
\hline 010 & 14.6 & 41 & pow. tarnogórski \\
\hline 010 & 10.4 & 30 & m. Bytom \\
\hline 010 & 12.4 & 51 & m. Dabrowa Górnicza \\
\hline 010 & 14.6 & 50 & m. Zabrze \\
\hline 020 & 12.6 & 39 & pow. tarnogórski \\
\hline & 11.8 & 45 & pow. zawierciański \\
\hline 020 & 12.6 & 55 & m. Bytom \\
\hline 020 & 12.6 & 35 & m. Zabrze \\
\hline 030 & 10.2 & so & pow. tarnogórski \\
\hline
\end{tabular}

Fig. 8. Examples of meteorological warnings: a) about exceeding the temperature threshold for a particular lead time and area, b) overall list of exceedance of the precipitation threshold for monitored administrative districts and all available lead times 

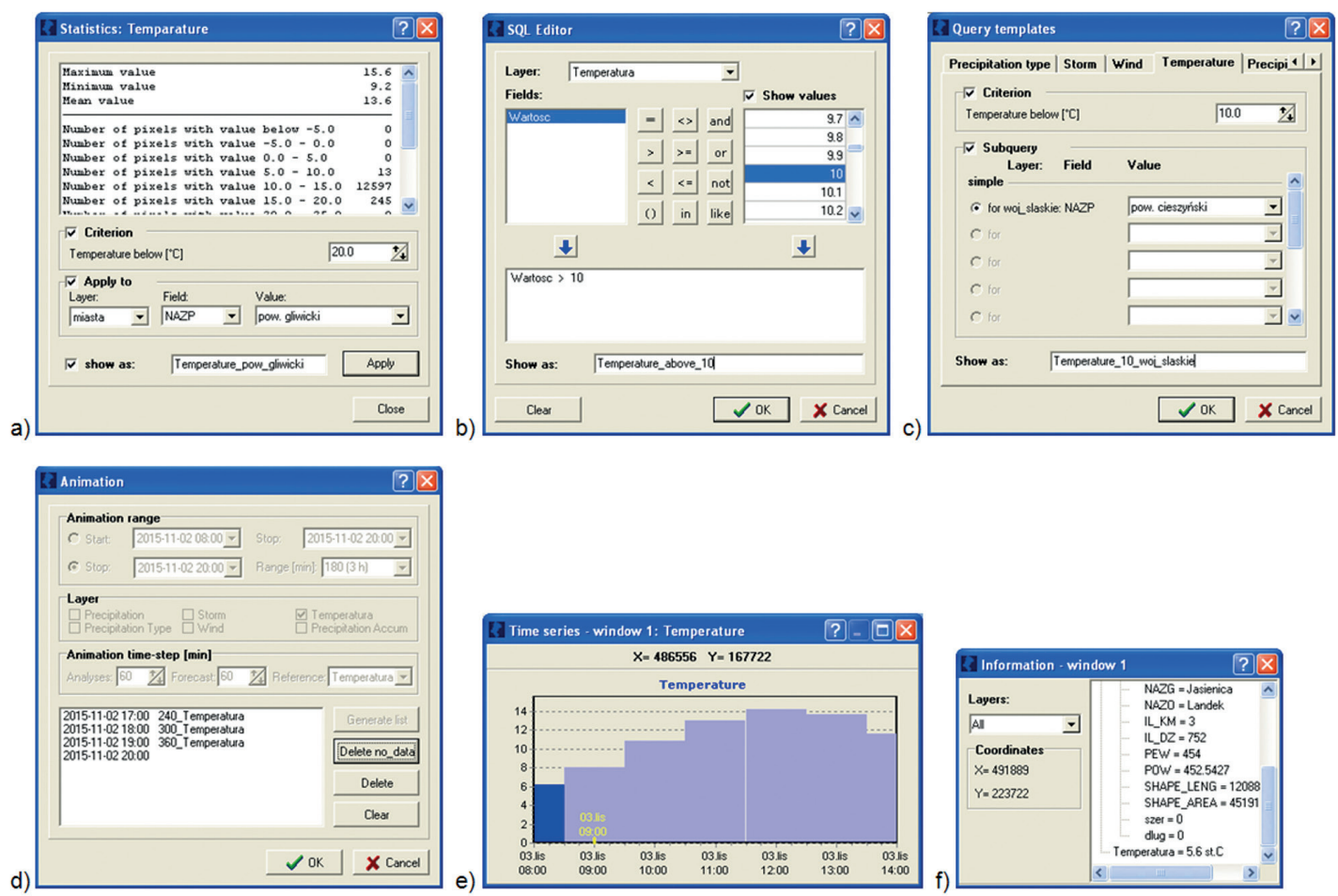

Fig. 9. Possibilities of weather analysis provided by MeteoGIS: a) statistics of meteorological field for selected area and threshold, b) SQL query window for simple queries, c) SQL query window with templates for relative queries, d) window for configuration of data animation, e) time series of temperature for a selected pixel with co-ordinates (X, Y) - the lighter colour indicates forecast values, f) window for display of information about all meteorological layers and GIS overlays for a selected pixel

- animations of visualised data which allows the tracing of movement and evolution of selected meteorological parameters and the prediction of their development in the near future (see fig. 9d),

- diagrams of data time series for selected meteorological fields in a given pixel; this enables investigation of past and forecast changes of the given parameter for the selected location (see Fig. 9e),

- access to values of all meteorological and GIS layers in a given pixel (see fig. 9f).

\section{Application management \\ 6.1. Schedules}

Some tasks can be performed in a schedule mode, defined by the user, to automate the work. The following schedules are available in the MeteoGIS application:

- meteorological data acquisition: a user can set the frequency of data to be downloaded from the IMGW-PIB hosting server to the MeteoGIS dedicated database (see fig. 10a),

- generation of precipitation accumulations: both repetition time for aggregation of precipitation data and the accumulation time period (e.g. 1-hour, 3-hour or other) have to be defined (see fig. 10b),

- data archiving: the database is divided into two parts operational, i.e. keeping data for a preset time period, and historical (for events that need to be archived, e.g. for future analysis); data that meet criteria defined by a user are moved from the operational to the historical part of the database (see fig. 10c).

\subsection{System manager}

The MeteoGIS manager tool is responsible for the management of the system (see fig. 11). Current information about incoming data, its storage in the database, the current status of scheduled tasks, and changes in system configuration are displayed in a message window within the manager. Errors in data inflow and the state of the system are signalled by a yellow or red bulb. The appearance of any meteorological warning is indicated by a red envelope; the envelope remains red until all the warnings have been read.

A user with administrator's rights to the MeteoGIS manager can manage user accounts, their workspaces, and geographical maps (GIS layers) with a set of supplied tools. Moreover, an administrator can set some more advanced parameters within the MeteoGIS system (e.g. related to data transmission from IMGW-PIB), parameters of schedules for data downloading, precipitation accumulation, moving data to the archive, and configuration of meteorological warnings. 

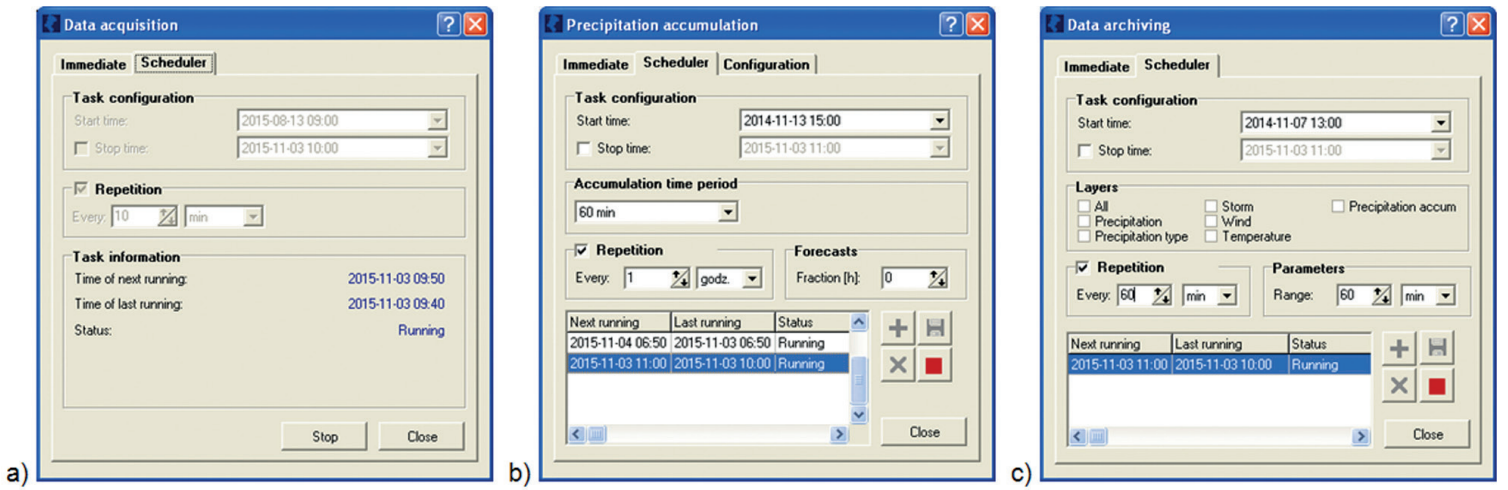

Fig. 10. Windows of configuration of schedules for: a) data downloading from the IMGW-PIB server, b) generation of precipitation accumulation, c) data archiving (moving data from operational to historical part of the database)

\section{Example: local event of heavy precipitation}

The combination of meteorological data with a high spatial resolution and GIS techniques allows the comprehensive analysis of data for selected geographical objects, such as districts, catchments, etc. An example of such analysis by means of the MeteoGIS application is presented below. The starting point, apart from the precipitation accumulation field, is an administrative map of districts within the Voivodeship. If some specific districts are selected, analysis of the precipitation field for them can be carried out using either the built-in statistical module or GIS-based tools.

In figure 12, a geographical object consisting of smaller administrative units within a selected district (Bytom) is presented within pink borders. The field can be used as an overlay for meteorological data, such as precipitation accumulation (an example from 2 June 2015, 1200 UTC). The precipitation data can be analysed using built-in statistical tools to get statistical characteristics like mean, maximum, and number of pixels in relevant precipitation classes for the selected objects or the whole system domain over the preset threshold.

Moreover, GIS-based tools enable the conducting of visual analysis of an event. Various kinds of SQL queries can be employed to perform such an investigation: simple, relative and template ones. All the tools are intuitive and easy to use.

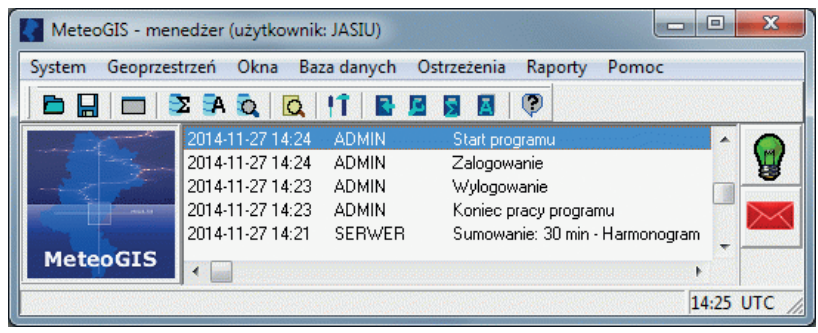

Fig. 11. The MeteoGIS system manager. Signalisation of the system status (green/yellow/red bulb) and meteorological warnings (grey/red envelope) visible on the right
In figure 13, examples of the simple SQL query are presented. For instance, the object like this one from fig. 12 can be selected and saved as a GIS layer and then analysis of meteorological fields can be performed, e.g. to show precipitation over a selected area defined by overlays (fig. 13a) or exceeding a given threshold. A relative SQL query combines two layers or the results of the simple queries. The result of the relative query in this case is a field of precipitation above the threshold for a selected geographical object.

For users not familiar with SQL syntax, templates of all kinds of queries (simple and relative) can be generated for frequently needed queries, which users then have to fill in with proper values. In figure $13 \mathrm{~b}$ an example of the use of such a template is presented. The query is related to the same area as in fig. 13a and for precipitation over this area, applying any threshold. In the example the threshold is set to $5 \mathrm{~mm}$.

Temporal analysis of meteorological fields is possible not only by animation of subsequent data, but also by viewing diagrams of each monitored quantity for a selected location (pixel). In figure 14, examples of hyetograph, wind speed, and temperature are presented, where for the given pixel such diagrams are available for a user-defined time period including past and predicted values.

\section{Summary}

Providing the end user with real-time and high-resolution (spatial and temporal) multi-source information and suitable processing tools is the essential condition for meteorological risk assessment. The MeteoGIS system integrates various kinds of meteorological data from different measurement and processing systems, both analyses and nowcasts. All gathered data and information can be thoroughly analysed in order to assess the risk of natural hazards, taking advantage of GIS techniques and dedicated tools, like warning generation, precipitation aggregation, etc. 


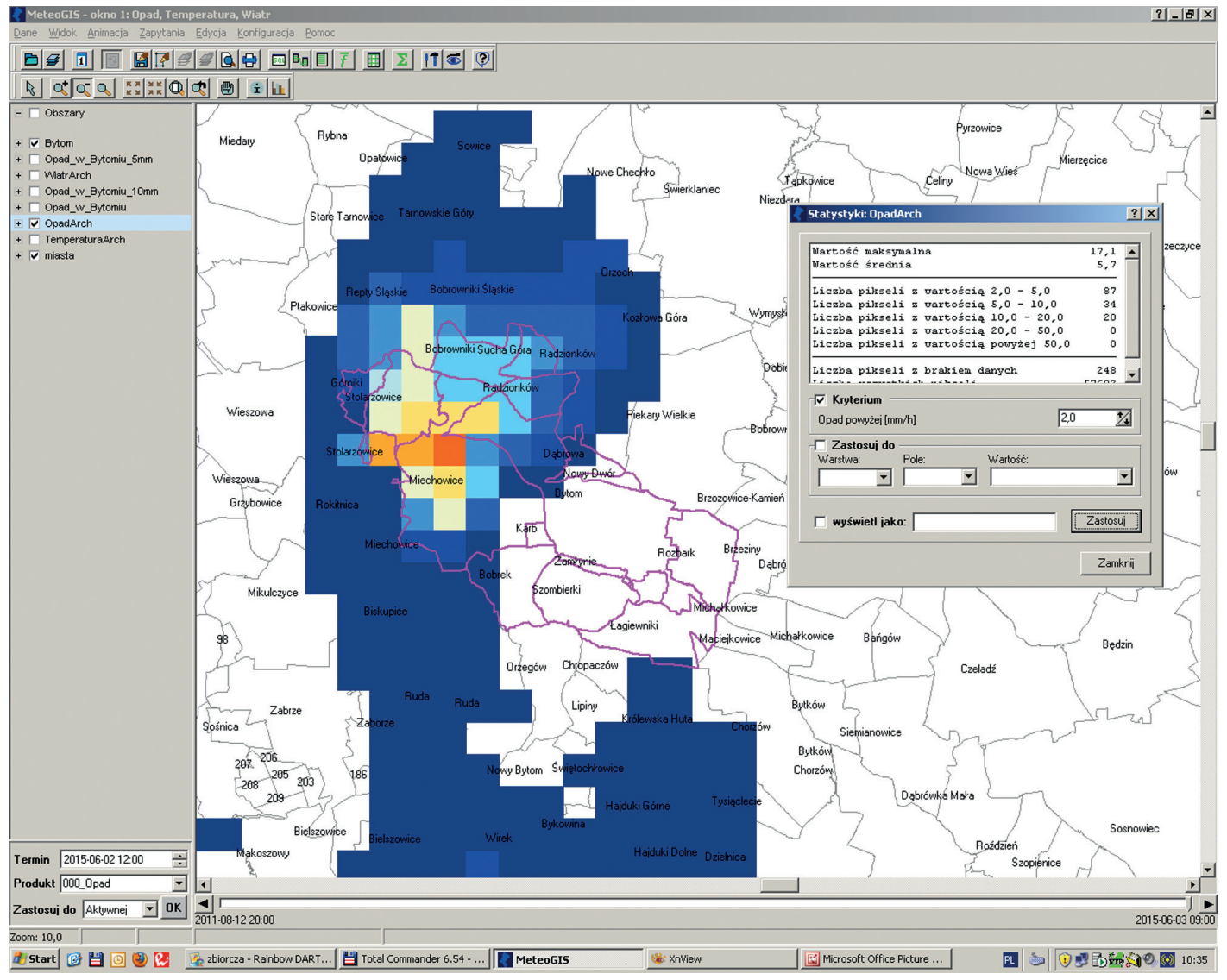

Fig. 12. Selected geographical object (administrative units of Bytom marked in pink colour) and precipitation field (2 June 2015, 1200 UTC). In the upper right corner - a sub-window with statistics of the exceedance of $2 \mathrm{~mm}$ precipitation (overall statistics: mean, maximum, and areas according to particular precipitation classes)

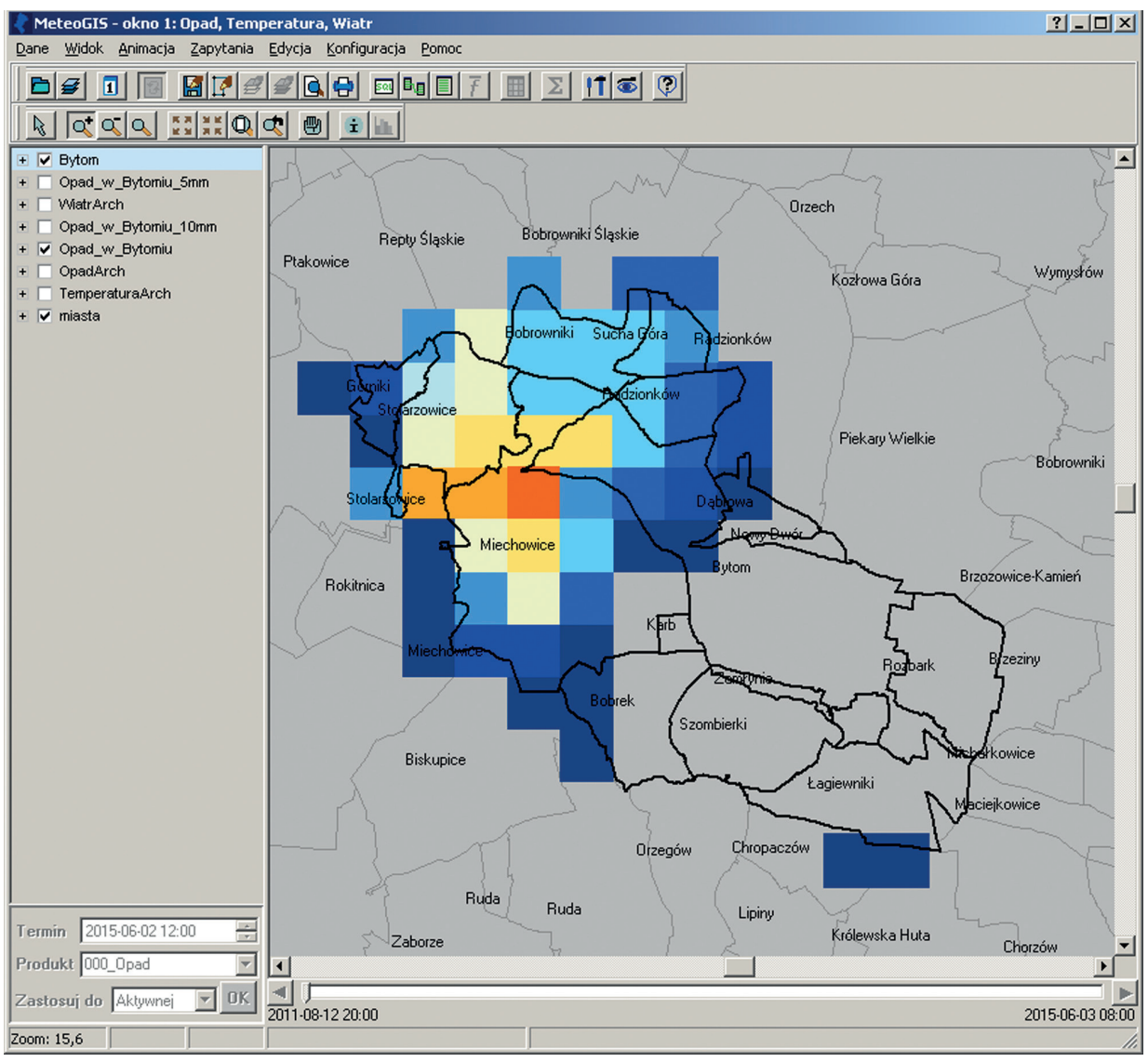

Fig. 13a. Windows with precipitation field shown in fig. 12 after using SQL queries: precipitation over selected area (city of Bytom) 


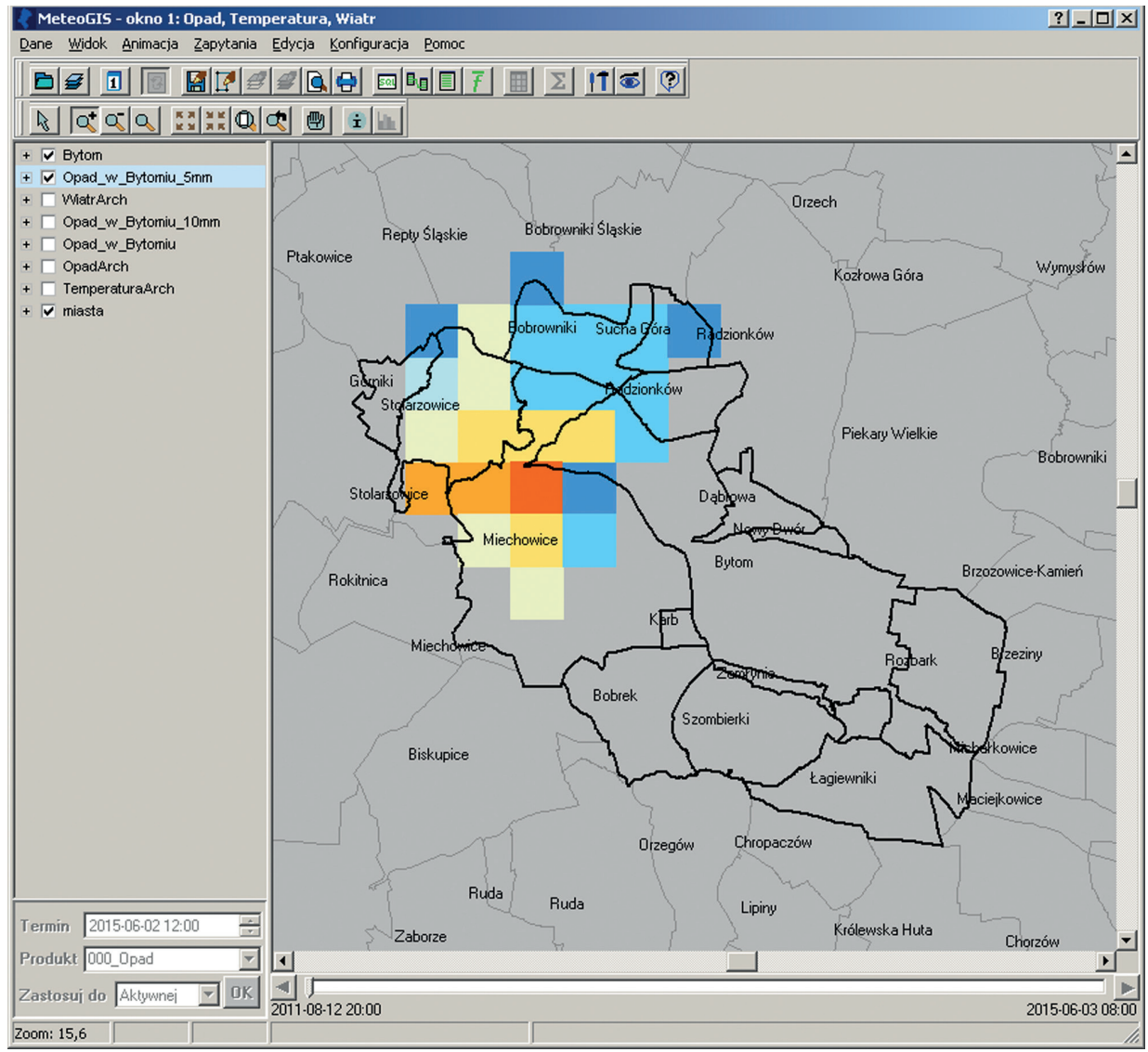

Fig. 13b. Windows with precipitation field shown in fig. 12 after using SQL queries: the same data but only precipitation over preset threshold $(5 \mathrm{~mm})$ is displayed

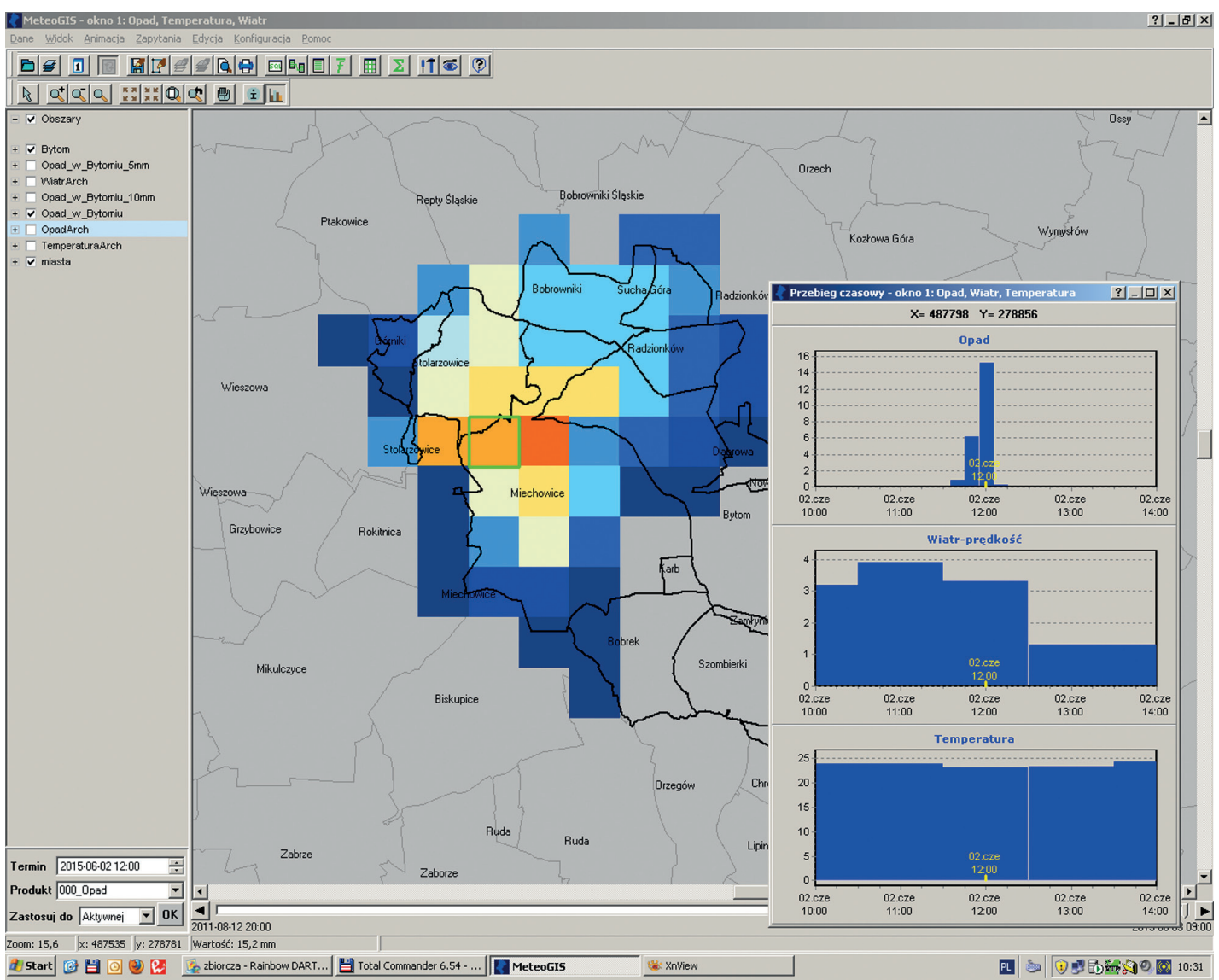

Fig. 14. Windows with a precipitation field shown in fig. 13a with time series displayed for a selected pixel marked by a green square. The sub-window in the lower right corner includes (from top): precipitation, wind speed, and temperature for the pixel 
Table 1. Input data used by MeteoGIS system

\begin{tabular}{|l|c|l|}
\hline \multicolumn{1}{|c|}{ Data kind } & Data source & \multicolumn{1}{c|}{ Description } \\
\hline $\begin{array}{l}\text { Precipitation } \\
\text { (10-min accumulation) }\end{array}$ & $\begin{array}{c}\text { RainGRS, } \\
\text { INCA-PL }\end{array}$ & $\begin{array}{l}\text { Analyses of precipitation as RainGRS products; forecasts as extrapolation forecasts } \\
\text { generated from the analyses merged with AROME ones }\end{array}$ \\
\hline $\begin{array}{l}\text { Precipitation } \\
\text { (other accumulations) }\end{array}$ & Computed by MeteoGIS from 10-min precipitation accumulations \\
\hline Precipitation type & INCA-PL & Analyses and forecasts generated by AROME \\
\hline Temperature & INCA-PL & Analyses and forecasts generated from AROME-derived data modified by measurements \\
\hline $\begin{array}{l}\text { Wind } \\
\text { (speed and direction) }\end{array}$ & INCA-PL & Analyses and forecasts generated from AROME-derived data modified by measurements \\
\hline Lightning & PERUN & Only observations (no forecasts) - locations of individual strikes \\
\hline
\end{tabular}

Although the MeteoGIS system was developed for a specific user, a civil protection department of the regional authorities of the Silesian Voivodeship, it is adaptable for different kinds of users. It was designed for anyone who needs fast, clear and detailed information about weather conditions. After initial user-specific configuration, weather monitoring with the system requires a minimal level of user interaction thanks to its automatic mode of operation. One of the most important tasks is the automatic generation of warnings about severe weather phenomena. In the monitored area (Upper Silesia) heavy rains (causing flash floods), thunderstorms, extremely high and low temperatures, and strong winds are the ones that need particular attention from civil protection services. Moreover, a user can perform advanced analysis of relevant events.

The quality of visualised data is a very important issue. Radar measurements provide high-resolution data, however, this is contaminated with a lot of spurious echoes (Michelson et al., 2005; Villarini, Krajewski 2010; Ośródka et al. 2014) that can degrade its reliability. The quality is systematically being improved by the modernisation of measurement networks and progress in postprocessing algorithms, e.g. weather radars within the POLRAD network are still being upgraded. New products based on Meteosat data are being developed using more and more advanced approaches. Moreover, the spatial resolution of NWP models is increasing (2.5 km at present), and new nowcasting approaches are being successively implemented. Thanks to the employment of products generated by the RainGRS system as precipitation field analysis, which takes advantage of the good points of data from rain gauges, weather radars, and satellites, the final quality of precipitation fields is significantly improved. From the MeteoGIS user's point of view, such an improvement in data quality is a continuous process.

Acknowledgments. The MeteoGIS system was developed for the regional authority of Upper Silesia (Silesian Voivodeship Office in Katowice) with financial support from the Voivodeship Fund for Environmental Protection and Water Management in Katowice.

Bibliography

Conway J.W., Eilts M.D., 2004, The HydroMet Decision Support System: new applications in hydrology, [in:] Proceedings of ERAD, Copernicus GmbH, 525-527

Conway J.W., Formentini G., Lago L., Rossa A., 2006, The Hydromet Decision Support System: operational application in hydrometeorology and flash flood prediction, [in:] Proceedings of ERAD, Copernicus GmbH, 444-447

Del Greco S., Ansari S., 2006, Radar visualization and data exporter tools to support interoperability and the Global Earth Observation System of Systems (GEOSS), from the National Oceanic and Atmospheric Administration's (NOAA's) National Climatic Data Center (NCDC), [in:] Proceedings of ERAD, Copernicus GmbH ,303-306

Einfalt T., Szturc J., Ośródka K., 2010, The quality index for radar precipitation data: a Tower of Babel?, Atmospheric Science Letters, 11 (2), 139-144, DOI: 10.1002/asl.271

Haiden T., Kann A., Wittmann C., Pistotnik G., Bica B., Gruber C., 2011, The Integrated Nowcasting through Comprehensive Analysis (INCA) system and its validation over the Eastern Alpine Region, Weather and Forecasting, 26 (2), 166-183, DOI: 10.1175/2010WAF2222451.1

Jurczyk A., Ośródka K., Tkocz G., Szturc J., 2009, MeteoGIS: system for monitoring of hazardous meteorological phenomena in the Silesian Voivodeship (in Polish), Wiadomości MHGW, 3, 3-16

Kann A., Pistotnik G., Bica B., 2012, INCA-CE: A Central European initiative in nowcasting severe weather and its applications, Advances in Science and Research, 8, 67-75, DOI: 10.5194/asr-8-67-2012

Konarski J., Gajda W., Dziewit Z., Barański P., 2008, Severe winter thunderstorm in Poland, case study, $20^{\text {th }}$ International Lightning Detection Conference; $2^{\text {nd }}$ International Lightning Meteorology Conference, 21-25 April, Tucson, USA, 8 pp., available at http://www.vaisala.com/en/events/ildcilmc/Documents/Se- 
vere $\% 20$ Winter $\% 20$ Thunderstorm $\% 20$ in $\% 20$ Poland $\% 20$ Case\%20Study.PDF (data access 26.11.2015)

Köhler P., Müller M., Sanders M., Wächter J., 2006, Data management and GIS in the Center for Disaster Management and Risk Reduction Technology (CEDIM): from integrated spatial data to the mapping of risk, Natural Hazards and Earth System Sciences, 6, 621-628, DOI: 10.5194/ nhess-6-621-2006

Kundzewicz Z.W., Szamałek K., Kowalczak P., 1999, The Great Flood of 1997 in Poland, Hydrological Sciences Journal, 44 (6), 855-870, DOI: 10.1080/02626669909492285

Michelson D., Einfalt T., Holleman I., Gjertsen U., Friedrich K., Haase G., Lindskog M., Jurczyk A., 2005, Weather Radar Data Quality in Europe - Quality Control and Characterization. Review, COST 717 Working Document WDF_ MC_200403_1, Luxembourg, 92 pp.

NWC SAF, 2013, SAFNWC/MSG Basic Documents, available at http://www.nwcsaf.org/HD/MainNS.jsp (data access 26.11.2015)

Ośródka K., Jurczyk A., Tkocz G., Szturc J., 2008, The MeteoGIS: radar-based system for monitoring severe meteorological phenomena, [in:]Proceedings of ERAD, Copernicus $\mathrm{GmbH},(\mathrm{CD})$

Ośródka K., Szturc J., Jurczyk A., 2014, Chain of data quality algorithms for 3-D single-polarization radar reflectiv- ity (RADVOL-QC system), Meteorological Applications, 21 (2), 256-270, DOI: 10.1002/met.1323

Seity Y., Brousseau P., Malardel S., Hello G., Bénard P., Bouttier F., Lac C., Masson V., 2011, The AROME-France Convective-Scale Operational Model, Monthly Weather Review, 139 (3), 976-991, DOI: 10.1175/2010MWR3425.1

Sinclair S., Pegram G., 2005, Combining radar and rain gauge rainfall estimates using conditional merging, Atmospheric Science Letters, 6 (1), 19-22, DOI: 10.1002/asl.85

Szturc J., Dziewit Z., 2005, Status and perspectives on using radar data: Poland, [in:] Use of Radar Observations in Hydrological and NWP Models. COST Action 717 Final Report, A. Rossa, M. Bruen, D. Frühwald, B. Macpherson, I. Holleman, D. Michelson, S. Michaelides (eds.), 218-221

Szturc J., Jurczyk A., Ośródka K., Struzik P., Otop I., 2014, Estimation of surface precipitation field based on multi-source data and quality information (in Polish), Monografie Komitetu Gospodarki Wodnej PAN, XX (2), 19-30

Villarini G., Krajewski W.F., 2010, Review of the different sources of uncertainty in single polarization radar-based estimates of rainfall, Surveys in Geophysics, 31 (1), 107-129, DOI: 10.1007/s10712-009-9079-x 
